\title{
Pemphigus vulgaris and mucous membrane pemphigoid: Update on etiopathogenesis, oral manifestations and management
}

\author{
Fadi Ata-Ali ${ }^{1}$, Javier Ata-Ali ${ }^{2}$ \\ ${ }^{1}$ DDS. Valencia University Medical and Dental School. \\ ${ }^{2}$ DDS. Master in Oral Medicine and Surgery. Master in Oral Surgery and Implantology. Valencia University Medical and Dental \\ School. Valencia (Spain)
}

Correspondence:

Clínicas Odontológicas. Piso I

Gascó Oliag 1

46021-Valencia (Spain)

E-mail: javiataali@hotmail.com

\section{Abstract}

Introduction: The treatment of oral mucosal disorders must be based on an early and correct diagnosis. Pemphigus vulgaris (PV) and mucous membrane pemphigoid (MMP) are among the diseases that pose the greatest diagnostic difficulties for dentists, with scores of 7.35 and 8.03 , respectively, on a scale from 0-10.

Objective: To conduct a literature review on PV and MMP, and to summarize the case series involving more than two patients with these diseases.

Material and Methods: A PubMed - Medline search was carried out, using the key words "pemphigus vulgaris" and "oral mucous membrane pemphigoid". The search was limited to "case reports" and "dental journals", and yielded a total of 122 articles on PV and 68 on MMP. The review considered only those accessible publications involving series of over two patients.

Results: Seven articles on PV and 5 on MMP, involving series of over two patients, were finally included.

Conclusions: A review has been made of the most recent literature on PV and MMP, documenting those series reporting over two patients.

Key words: Oral, pemphigus vulgaris, mucous membrane pemphigoid, treatment, autoimmune. 


\section{Introduction}

The treatment of oral mucosal disorders must be based on an early and correct diagnosis. Pemphigus vulgaris (PV) and mucous membrane pemphigoid (MMP) are among the diseases that pose the greatest diagnostic difficulties for dentists, with scores of 7.35 and 8.03, respectively, on a scale from 0-10 (1).

Both PV and MMP are chronic, autoimmune mucocutaneous diseases affecting the oral mucosa and which can generate doubts regarding their initial diagnosis.

The present study offers a literature review on PV and
MMP, and summarizes the case series involving more than two patients with these diseases.

A PubMed - Medline search was carried out, using the key words "pemphigus vulgaris" and "oral mucous membrane pemphigoid". Seven articles were published in 2010. The search was limited to "case reports" and "dental journals", and yielded a total of 122 articles on PV and 68 on MMP. The review considered only those accessible publications involving series of over two patients. Seven articles on PV and 5 on MMP were finally included (Tables 1 and 2).

\begin{tabular}{|c|c|c|c|c|c|c|}
\hline Article & $\begin{array}{l}\text { No. pa- } \\
\text { tients }\end{array}$ & $\begin{array}{l}\text { Mean age } \\
\text { (range) }\end{array}$ & $\begin{array}{c}\text { Gender } \\
(\mathbf{F} / \mathbf{M})\end{array}$ & $\begin{array}{l}\text { Evolution } \\
\text { (months) }\end{array}$ & Location & $\begin{array}{c}\text { Skin/mucosa } \\
\text { lesions (Yes/No) }\end{array}$ \\
\hline $\begin{array}{c}\text { Sirois et al. } 2000 \\
\text { (2) }\end{array}$ & 42 & $56.1(27-68)$ & $30 / 12$ & - & $\begin{array}{c}\text { Oral mucosa, } \\
\text { gums and palate }\end{array}$ & - \\
\hline $\begin{array}{c}\text { Davenport et al. } \\
2001(3)\end{array}$ & 33 & 56.5 (27-79) & $25 / 8$ & - & - & - \\
\hline $\begin{array}{l}\text { Camacho-Alon- } \\
\text { so et al. } 2005 \text { (4) }\end{array}$ & 14 & $44.78(21-87)$ & $10 / 4$ & $\begin{array}{c}0.75-72 \\
\text { (mean 11.66) }\end{array}$ & $\begin{array}{c}\text { Cheek mucosa, } \\
\text { lip, gums and } \\
\text { palate }\end{array}$ & $6 / 8$ \\
\hline $\begin{array}{c}\text { Iamaroon et al. } \\
2006(5)\end{array}$ & 18 & $37.7(18-55)$ & $12 / 6$ & $\begin{array}{c}1-98 \text { (mean } \\
12)\end{array}$ & $\begin{array}{l}\text { Gums, oral mu- } \\
\text { cosa and palate }\end{array}$ & - \\
\hline $\begin{array}{c}\text { Shamim et al } \\
2007(6)\end{array}$ & 20 & 42.3 (20-69) & $12 / 8$ & $1-12($ mean 8) & $\begin{array}{l}\text { Oral mucosa, } \\
\text { palate and lip }\end{array}$ & - \\
\hline $\begin{array}{c}\text { Shamim et al. } \\
2008(7)\end{array}$ & 71 & $42.73(15-70)$ & $45 / 26$ & $\begin{array}{c}1-12 \text { (mean } \\
5.5)\end{array}$ & $\begin{array}{l}\text { Oral mucosa, } \\
\text { palate, lip and } \\
\text { tongue }\end{array}$ & $38 / 33$ \\
\hline $\begin{array}{c}\text { Arisawa et al. } \\
2008(8)\end{array}$ & 4 & $\begin{array}{c}\text { 4th decade of } \\
\text { life }\end{array}$ & $2 / 2$ & $1-12$ & $\begin{array}{l}\text { Oral mucosa, } \\
\text { alveolar mucosa, } \\
\text { soft palate }\end{array}$ & \\
\hline
\end{tabular}

No. patients $=$ Number of patients

Gender $(\mathbf{F} / \mathbf{M})=$ Gender $(\mathrm{F}=$ female $/ \mathrm{M}=$ male $)$

Table 1. Summary of the case series published in the literature, involving more than two patients with pemphigus vulgaris (PV).

\begin{tabular}{|c|c|c|c|c|c|c|c|}
\hline Article & $\begin{array}{c}\text { No. pa- } \\
\text { tients }\end{array}$ & $\begin{array}{c}\text { Age (mean/ } \\
\text { range) }\end{array}$ & $\begin{array}{c}\text { Gender } \\
(\text { F/M) }\end{array}$ & $\begin{array}{c}\text { Evolution } \\
\text { (months) }\end{array}$ & Location & Extent & $\begin{array}{c}\text { Skin/mucosa } \\
\text { lesions (Yes/No) }\end{array}$ \\
\hline $\begin{array}{c}\text { Farrel et al. } \\
1998 \text { (9) }\end{array}$ & 3 & $11.66(8-14)$ & $3 / 0$ & 3 & Gums and lips & 2 & $3 / 0$ \\
\hline $\begin{array}{c}\text { Assman et al. } \\
2004 \text { (10) }\end{array}$ & 2 & $66.5(66-67)$ & $1 / 1$ & 84 & $\begin{array}{c}\text { Oral mucosa } \\
\text { and gums }\end{array}$ & 2 & $0 / 2$ \\
\hline $\begin{array}{c}\text { España et al. } \\
2005(11)\end{array}$ & 5 & $55.8(41-69)$ & $2 / 3$ & 66 & $\begin{array}{c}\text { Oral mucosa, } \\
\text { cheek mucosa, } \\
\text { gums and palate }\end{array}$ & 1 & $4 / 1$ \\
\hline $\begin{array}{c}\text { Freitas et al. } \\
2008(12)\end{array}$ & 2 & $65(52-78)$ & - & - & $\begin{array}{c}\text { Cheek mucosa, } \\
\text { hard and soft } \\
\text { palate }\end{array}$ & 2 & $2 / 0$ \\
\hline $\begin{array}{c}\text { Arisawa et al. } \\
2008 \text { (8) }\end{array}$ & 6 & $(20-80)$ & $3 / 3$ & 11 & $\begin{array}{c}\text { Alveolar mu- } \\
\text { cosa, lips, oral } \\
\text { mucosa }\end{array}$ & 1 & $1 / 5$ \\
\hline
\end{tabular}

No. patients $=$ Number of patients

Gender $(\mathbf{F} / \mathbf{M})=$ Gender $(\mathrm{F}=$ female $/ \mathrm{M}=$ male $)$

Table 2. Summary of the case series published in the literature, involving more than two patients with mucous membrane pemphigoid (MMP). 


\section{Pemphigus Vulgaris (PV)}

$\mathrm{PV}$ is a serious autoimmune disorder with mucocutaneous manifestations characterized by the development of blisters on the skin and/or mucosal membranes (13). Six types of pemphigus have been established: vulgaris, vegetans, erythematosus, foliaceus, paraneoplastic pemphigus, and pemphigus IgA (14).

PV usually manifests between the fourth and fifth decades of life, and affects both males and females equally (15). The reported incidence is $0.1-0.5$ cases per 100,000 inhabitants and year (16).

The disease is characterized by the production of $\mathrm{IgG}$ and IgM antibodies within the intercellular space, targeted against desmosomal cell adhesion molecules such as desmoglein 3 and (in 50\% of all cases) desmoglein 1 (16). The presence of HLA class I (HLA-A10, HLAA26) and HLA class II genes (DR4, DR14) has been associated with a certain predisposition to develop the disease (17).

In $60 \%$ of all cases the symptoms initially manifest in the oral cavity (3), though according to some authors the proportion reaches $90 \%$ (16). Clinically, the lesions consist of small and asymptomatic blisters that rupture easily, giving rise to painful and bleeding erosions. While any part of the oral cavity can be affected, the most common locations are the friction zones such as the cheek mucosa, tongue, palate, lower lip and gums. The lesions typically develop over several months in the oral cavity before spreading to the skin and other mucosal zones such as the pharynx, larynx, esophagus or genital mucosa $(3,4)$.

A direct relationship has been reported between PV and periodontal tissue involvement in the form of increased plaque accumulation, increased pocket depth, and attachment loss (18).

The tentative clinical diagnosis must be confirmed by means of complementary tests such as exfoliative cytology, histopathological study, direct and indirect immunofluorescence, and immunoprecipitation tests. Exfoliative cytology in the blister or vesicle phase of the disease reveals Tzanck acantholytic cells with Papanicolaou staining (19). The histological study of PV initially identifies intercellular edema in the suprabasal portion of the stratum spinosum, with the formation of clefts and acantholysis, leading to the formation of blisters. The identification of acantholytic cells floating in the stratum spinosum is useful, though direct immunofluorescence (DIF) is required to confirm the diagnosis (20). DIF reveals marking of the epithelial cell surface, indicating the presence of immunoglobulin deposits on the keratinocyte membrane (intercellular space). In 100\% of the cases IgG deposits are observed in the epithelial intercellular spaces, while the presence of $\operatorname{IgM}$ deposits is much less frequent (17). Indirect immunofluorescence (IIF) in turn detects circulating antibodies targeted to the epithelial cell surface (anti-intercellular substance) fundamentally IgG4 and IgG1, and less commonly IgG3 $(17,21)$. At present, immunoprecipitation is regarded as the technique of choice for identifying the patient autoantibody target antigens. In this context, desmoglein 3 is targeted in PV, while desmoglein 1 is targeted in pemphigus foliaceus (in skin)(22).

The objective of treatment is to deal with the activity flare-ups as early as possible (23). In patients with nonprogressing oral lesions, moderate to high potency topical corticosteroids are recommended, applied 2-3 times a day, such as $0.05 \%$ fluocinolone acetonide or $0.05 \%$ clobetasol propionate $(24,25)$. In these patients it also may be useful to prescribe dapsone (125-150 mg daily) or tetracycline ( $2 \mathrm{~g} /$ day $)$ and nicotinamide $(1.5 \mathrm{~g} /$ day $)$ (21).

In patients with severe disease and spreading of the lesions to skin surfaces, corticosteroids are the treatment of choice, at a dose of 1-3 mg/kg/day during 6-10 weeks, with gradual reduction of the applied dose. In order to reduce the corticosteroid dose, such treatment is combined with immune suppressors such as cyclophosphamide $100 \mathrm{mg}$ /day (23), though doses of up to $200 \mathrm{mg}$ /day have also been used (21), or azathioprine $1-2 \mathrm{mg} / \mathrm{kg} /$ day. In relation to the latter, it is important to evaluate thiopurine methyltransferase, since the treatment efficacy and side effects are dependent upon the activity of this enzyme (23). Other options are chlorambucil 0.1-0.15 mg/ $\mathrm{kg} /$ day, cyclosporine A $5-8 \mathrm{mg} / \mathrm{kg} /$ day, mycophenolate mofetil (MMF) $35-45 \mathrm{mg} / \mathrm{kg} / \mathrm{day}$, and methotrexate 10$17.5 \mathrm{mg} /$ week. In refractory cases it is advisable to prescribe rituximab, plasmapheresis to reduce the presence of antibodies in serum (26), or pulse therapy comprising intravenous cyclophosphamide combined with dexamethasone at high doses $(15,21,23)$.

Although much less frequent than PV, paraneoplastic pemphigus is a variant in which the pemphigus lesions are secondary to a neoplastic process. This presentation is most often associated to hematological neoplasms (84\% of all cases), particularly non-Hodgkin lymphomas (42\%), chronic lymphocytic leukemia (29\%), Castleman's disease (10\%), and others - though cases have also been documented in non-hematological neoplastic processes $(16 \%$ of all cases $)(27,28)$.

\section{Mucous Membrane Pemphigoid (MMP)}

MMP is a chronic autoimmune disease of unknown etiology that manifests in the form of subepithelial blisters. Classically, the variants of MMP are bullous pemphigoid and mucous membrane or cicatricial pemphigoid - the latter being the most common presentation. It is more common in females, and the mean age at onset of the disease is in the fifth or sixth decade of life $(29,30)$. Presentations in children have also been described (31). The epidemiological characteristics of MMP are unclear, 
with a reported incidence of $1.5-9.5$ cases per 100,000 inhabitants and year (29).

MMP is characterized by the production of autoantibodies (mainly IgG)(97\%), C3 complement factor (78\%) and, to a lesser degree, IgA (27\%) and IgM (12\%), targeted to certain components of the basal lamina of the epithelium. An accumulation of IgG has been documented between laminin 5 and type IV collagen present at the dermal-epidermal junction (32). Different forms of MMP exhibit autoantibodies against different elements of this zone of the basal lamina: laminin 5 and 6 , antigen 180, and antigens BPAg 1 and BPAg $2(21,32)$.

Depending on the autoantibodies detected by immunoassay techniques, MMP can be classified into 6 subgroups: oral pemphigoid, anti-epiligrin pemphigoid, anti-BP Ag mucosal pemphigoid, ocular pemphigoid, a fifth group consists of patients with antibodies directed against more than one antigen, and anti-p200 pemphigoid (32). The oral, ocular and genital mucosas are the most commonly affected mucosal membranes, followed in decreasing order of frequency by the pharyngeal, laryngeal, nasal and esophageal mucosas. Within the oral cavity, the most frequently affected locations are the gums, followed by the soft and hard palate, the oral mucosa and the tongue. Clinically, the affected patients show blisters occupying the full thickness of the epithelium, and which can develop for hours or days before rupturing. When these blisters finally rupture, they leave pseudomembranes with irregularly shaped yellowish ulcerations surrounded by an erythematous halo. A positive Nikolsky sign is a common finding. The patients usually suffer bleeding, pain and desquamation of the oral mucosa. Occasionally, gingival inflammation in the absence of bacterial plaque can be observed, in the form of chronic desquamative gingivitis $(29,30)$, though pocket depth and attachment loss have not been found to be statistically significant (33).

Skin lesions are uncommon and are located on the face, neck, scalp, trunk and extremities (32). Ocular lesions are observed in approximately $40 \%$ of all patients with MMP, and tend to initially manifest as chronic conjunctivitis with burning sensation, irritation, photosensitivity and excessive tearing (lacrimation). The subsequent course can be characterized by symblepharon, ankyloblepharon and cicatricial bridles that can lead to blindness $(29,34)$.

The definitive diagnosis can only be established based on the histopathological data and immunofluorescence studies (30). Histologically, the disease is characterized by separation at basal membrane level, giving rise to a subepithelial blister $(29,35)$. The lamina propria shows a chronic inflammatory infiltrate composed of eosinophils, lymphocytes and neutrophils (32). Direct immunofluorescent techniques (DIF) are useful, since they reveal the presence of homogeneous IgG and $\mathrm{C} 3$ com- plement deposits along the junction between the connective tissue and epithelium.

Indirect immunofluorescence (IIF) in turn is able to detect circulating antibodies in the serum of the patient (34). However, in application to MMP, the sensitivity of this technique is very low in comparison with other diseases such as PV for example. Nevertheless, in some cases the IIF findings have been shown to be positive in patients with negative DIF results $(11,32)$.

The factors to be taken into account in treating MMP are its location, severity and progression rate. In low risk patients with lesions confined to the oral mucosa and/or skin, topical corticosteroids are advised, such as $0.1 \%$ triamcinolone acetonide, $0.05 \%$ fluocinolone acetonide, or $0.05 \%$ clobetasol propionate in orabase, applied 3-4 times a day during 9-24 weeks. In patients with isolated erosions, intralesional corticosteroid injections (triamcinolone in $5-10 \mathrm{mg} / \mathrm{ml}$ solution) can be used. In subjects presenting gingival lesions in the form of desquamative gingivitis, $0.05 \%$ clobetasol propionate is recommended, with nystatin 100,000 IU to avoid candidiasis overinfection $(32,34)$. When MMP affects the palate, esophagus or nasal mucosa, beclomethasone dipropionate or budesonide (50-200 $\mu \mathrm{g}$ ) can be prescribed (32). Topical $0.1 \%$ tacrolimus in pomade, associated to prednisone $40 \mathrm{mg} /$ day via the oral route has been reported to offer good results, with resolution of the lesions after three months of treatment, and offering a preventive effect against the disease (36). Depending on the patient response, other alternatives can be considered, such as $100 \mathrm{mg}$ of doxycycline a day for 8 weeks, or minocycline $50-100 \mathrm{mg} /$ day during 3-39 months, and nicotinamide 2-3 g/day $(32,34)$.

In high risk patients with multiple oral lesions, rapidly progressing spread of the disease to other mucosal membranes such as the eyes, genital, esophagus or nasopharyngeal zone, or recurrent lesions, the administration of prednisone $1-2 \mathrm{mg} / \mathrm{kg} / \mathrm{day}$, with gradual dose reduction, and immune suppressors such as cyclophosphamide $(0.5-2 \mathrm{mg} / \mathrm{kg} /$ day $)$, azathioprine $1-2 \mathrm{mg} /$ $\mathrm{kg}$ /day, or mycophenolate mofetil 2-2.5 g/day has been described $(21,23,32,34)$.

Another treatment option is dapsone $(50-200 \mathrm{mg} /$ day) for 12 weeks (23). Treatment is started with $25 \mathrm{mg}$ during three days, followed by $25 \mathrm{mg}$ increments every three days until reaching a dose of $100 \mathrm{mg}$, followed by boosting of the dosage to $150 \mathrm{mg}$ (34). Blood test monitoring is important in order to avid the appearance of side effects (23). Other drugs that have been used include methotrexate, which at low doses prevents the progression of conjunctival cicatrization in $72 \%$ of all patients, tumor necrosis factor-alpha, leflunomide or sulfonamide (regarded as an alternative to dapsone, administered at a dose of 1.5-3 g/day). Less commonly used options in turn are intravenous immunoglobulins (1-2 g/ kg/cycle), 
plasmapheresis in patients with eye lesions refractory to corticosteroids and immune suppressors and, as a last option, surgery to avoid complications such as blindness, esophageal strictures or upper airway stenosis (32).

\section{References}

1. Ergun S, Ozel S, Koray M, Kürklü E, Ak G, Tanyeri H. Dentists' knowledge and opinions about oral mucosal lesions. Int $\mathrm{J}$ Oral Maxillofac Surg. 2009;38:1283-8.

2. Sirois D, Leigh JE, Sollecito TP. Oral pemphigus vulgaris preceding cutaneous lesions: recognition and diagnosis. J Am Dent Assoc. 2000;131:1156-60.

3. Davenport S, Chen SY, Miller AS. Pemphigus vulgaris: clinicopathologic review of 33 cases in the oral cavity. Int J Periodontics Restorative Dent. 2001;21:85-90.

4. Camacho-Alonso F, López-Jornet P, Bermejo-Fenoll A. Pemphigus vulgaris. A presentation of 14 cases and review of the literature. Med Oral Patol Oral Cir Bucal. 2005;10:282-8.

5. Iamaroon A, Boonyawong P, Klanrit P, Prasongtunskul S, Thongprasom K. Characterization of oral pemphigus vulgaris in Thai patients. J Oral Sci. 2006;48:43-6.

6. Shamim T, Varghese VI, Shameena PM, Sudha S. Oral pemphigus vulgaris: clinicopathologic study of 20 cases. Indian J Pathol Microbiol. 2007;50:498-501.

7. Shamim T, Varghese VI, Shameena PM, Sudha S. Pemphigus vulgaris in oral cavity: clinical analysis of 71 cases. Med Oral Patol Oral Cir Bucal. 2008;13:E622-6.

8. Arisawa EA, Almeida JD, Carvalho YR, Cabral LA. Clinicopathological analysis of oral mucous autoimmune disease: A 27-year study. Med Oral Patol Oral Cir Bucal. 2008;13:E94-7.

9. Farrell AM, Kirtschig G, Dalziel KL, Allen J, Dootson G, Edwards S, Wojnarowska F. Childhood vulvar pemphigoid: a clinical and immunopathological study of five patients. Br J Dermatol. 1999;140:308-12.

10. Assmann T, Becker J, Ruzicka T, Megahed M. Topical tacrolimus for oral cicatricial pemphigoid. Clin Exp Dermatol. 2004;29:674-6.

11. España A, del Olmo J, Marquina M, Fernández S, Panizo C, Maldonado M. Mucous membrane pemphigoid: clinical manifestations and treatment with corticosteroids, dapsone and cyclophosphamide in 5 patients. Actas Dermosifiliogr. 2005;96:357-64.

12. Freitas VA, Becker HM, Guimarães RE, Franco LP, Guimarães FF, Martins MF, et al. Cicatricial pemphygoid in the upper aerodigestive tract: report of two cases. Braz J Otorhinolaryngol. 2008;74:941-4.

13. Akman A, Kacaroglu H, Yilmaz E, Alpsoy E. Periodontal status in patients with pemphigus vulgaris. Oral Dis. 2008;14:640-3.

14. Hashimoto T. Recent advances in the study of the pathophysiology of pemphigus. Arch Dermatol Res. 2003;295:S2-11.

15. Scully C, Challacombe SJ. Pemphigus vulgaris: update on etiopathogenesis, oral manifestations, and management. Crit Rev Oral Biol Med. 2002;13:397-408.

16. Dagistan S, Goregen M, Miloglu O, Cakur B. Oral pemphigus vulgaris: a case report with review of the literature. J Oral Sci. 2008;50:359-62.

17. Martel P, Joly P. Pemphigus: autoimmune diseases of keratinocyte adhesion molecules. Clin Dermatol. 2001;19:662-74.

18. Thorat MS, Raju A, Pradeep AR. Pemphigus vulgaris: effects on periodontal health J Oral Sci. 2010;52:449-54.

19. Mignona MD, Muzio L, Zeppa P, Ruocco V, Bucci E. Immunocytochemical detection of autoantibody deposits in Tzanck smears from patients with oral pemphigus. J Oral Pathol Med. 1997;26:254-7.

20. Singh M, Demetriades N, Papas A, Gagari E. A clinico-pathologic correlation. Pemphigus vulgaris. J Mass Dent Soc. 2008;56:42-4.

21. Knudson RM, Kalaaji AN, Bruce AJ. The management of mucous membrane pemphigoid and pemphigus. Dermatol Ther. 2010;23:268-80.

22. Weinberg MA, Insler MS, Campen RB. Mucocutaneous features of autoimmune blistering diseases. Oral Med Oral Pathol Oral Radiol
Endod. 1997;84:517-34.

23. López-Jornet P, Bermejo-Fenoll A. Treatment of pemphigus and pemphigoids. Med Oral Patol Oral Cir Bucal. 2005;10:410-1.

24. Hashimoto T. Treatment strategies for pemphigus vulgaris in Japan. Expert Opin Pharmacother. 2008;9:1519-30.

25. Prajapati V, Mydlarski PR. Advances in pemphigus therapy. Skin Therapy Lett. 2008;13:4-7.

26. Aoyama Y, Nagasawa C, Nagai M, Kitajima Y. Severe pemphigus vulgaris: successful combination therapy of plasmapheresis followed by intravenous high-dose immunoglobulin to prevent rebound increase in pathogenic IgG. Eur J Dermatol. 2008; 18:55760.

27. Batista MD, Takano D, Lopes RD, Enokihara MM, Michalany NS, de Almeida FA. Paraneoplastic pemphigus associated with nonHodgkin lymphoma. Paraneoplastic pemphigus associated with non-Hodgkin lymphoma. Dermatol Online J. 2008;14:11

28. Yan Z, Hua H, Gao Y. Paraneoplastic pemphigus characterized by polymorphic oral mucosal manifestations--report of two cases. Quintessence Int. 2010;41:689-94

29. Schifter M, Yeoh SC, Coleman H, Georgiou A.Oral mucosal diseases: the inflammatory dermatoses. Aust Dent J. 2010;55:23-38.

30. Talacko AA, Gordon AK, Aldred MJ. The patient with recurrent oral ulceration. Aust Dent J. 2010;1:14-22.

31. Mostafa MI, Hassib NF, Nemat AH. Oral mucous membrane pemphigoid in a 6-year-old boy: diagnosis, treatment and 4 years follow-up. Int J Paediatr Dent. 2010;20:76-9.

32. Bagan J, Lo Muzio L, Scully C. Mucosal disease series. Number III. Mucous membrane pemphigoid. Oral Dis. 2005;11:197-218.

33. Lo Russo L, Guiglia R, Pizzo G, Fierro G, Ciavarella D, Lo Muzio L, et al. Effect of desquamative gingivitis on periodontal status: a pilot study. Oral Dis. 2010;16:102-7.

34. Scully C, Lo Muzio L.Oral mucosal diseases: mucous membrane pemphigoid. Br J Oral Maxillofac Surg. 2008;46:358-66.

35. Yeh SW, Ahmed B, Sami N, Razzaque Ahmed A. Blistering disorders: diagnosis and treatment. Dermatol Ther. 2003;16:214-23.

36. Assmann T, Burchardt T, Becker J, Ruzicka T, Megahed M. Topical immunomodulators: a therapeutic option for oral cicatricial pemphigoid. Hautarzt. 2004;55:390-2. 